\title{
Top Management Teams' Characteristics and Strategic Decision-Making: A Mediation of Risk Perceptions and Mental Models
}

\author{
Tungju Wu ${ }^{1,2}$, Yenchun Jim $\mathrm{Wu}^{3,4, *}$ (D), Hsientang Tsai ${ }^{5}$ and Yibin $\mathrm{Li}^{1,2}$ \\ 1 College of Business Administration, Huaqiao University, Quanzhou 362021, China; tjwu@hqu.edu.cn (T.W.); \\ liyibin@hqu.edu.cn (Y.L.) \\ 2 East Business Management Research Center, Huaqiao University, Quanzhou 362021, China \\ 3 National Taiwan Normal University, Taipei 10645, Taiwan \\ 4 National Taipei University of Education, Taipei 10671, Taiwan \\ 5 Department of Business Management, National Sun Yat-sen University, Kaohsiung 80424, Taiwan; \\ htt@mail.nsysu.edu.tw \\ * Correspondence: wuyenchun@gmail.com; Tel.: +886-2-7734-3996
}

Received: 2 November 2017; Accepted: 5 December 2017; Published: 7 December 2017

\begin{abstract}
Strategic decision-making is a key factor of sustainability and development in enterprises. Moreover, the top management team (TMT) of an enterprise constitutes the base for decision-making. This study employed structural equation modeling to analyze questionnaires regarding TMTs' characteristics and strategic decision-making, and tested the mediating effects of risk perceptions and mental models and the moderating effects of psychological ownership. We investigated 289 valid questionnaires on TMTs completed by representatives from enterprises in China and found risk perceptions and mental models that serve as a mediating factor and are affected by the TMTs' characteristics and decision-making. We also found that psychological ownership exerts moderating effects between TMTs' characteristics and decision-making. This paper concludes with a discussion of theoretical and managerial implications for enterprise owners.
\end{abstract}

Keywords: top management team; strategic decision-making; risk perception

\section{Introduction}

Enterprises are expanding and shifting toward group management amidst perpetual economic growth and industrial development. In addition, enterprise management has gradually shifted from employing leader-oriented strategies to employing co-management strategies in the form of top management teams (TMTs). A TMT comprises key executives within an organization who are responsible for the planning and execution of organizational strategies. Previous studies have noted that strategic decision-making is affected by the behavioral factors of TMTs [1,2]. Hambrick and Mason [3] introduced the upper echelon theory, stating that TMT characteristics (e.g., age, international experience, educational background) are closely associated with vender strategy selection and are reflected in the major decisions of many organizations.

A number of previous studies on the effects of TMT factors on decision-making in enterprises have asserted that international experience among top managers [4], tenure [4,5], scale of the organization [4], and number of reappointed executives in the TMT [6] all influence the members of a TMT when making strategic decisions. The present study focused on examining the effects of TMTs and job-related characteristics. In contrast to previous studies that have discussed TMTs and job-related characteristics in relation to enterprises in emerging markets, the present study adopted tenure heterogeneity [4] to reflect TMT members' levels of understanding of their organizations [7], and employed international 
experience, educational background heterogeneity, and functional background heterogeneity to represent TMT members' training, professional knowledge, and skill levels.

Regardless of style, team composition, and atmosphere, leadership is a crucial variable influencing organizational performance and decision-making. Many previous studies have observed that leadership style is the foremost environmental factor that directly affects performance, morale, and sense of satisfaction among subordinates [3]. The personality traits of top executives are the most prominent factors that influence the formation of leadership style and organizational culture. In the management pyramid, management is categorized into three levels, namely first-, middle-, and top-level management. Top managers are typically involved in the direction, strategy, leadership, effectiveness, and philosophy of a company. The duties of these managers are to characterize the vision of the organization, establish common organizational values and concepts, capitalize on opportunities, promote innovation, evaluate risk, and lead the organization in fulfilling its organizational objectives. Therefore, top managers are the most crucial assets of organizations, and their leadership styles are key to the successful or failed formation of organizational culture and the implementation of systems, which consequently affects business performance. Organizational culture is a type of consensus among employees in an organization that prompts them to think and act in unison. According to previous studies, organizational culture can be defined as the beliefs, expectations, and values formed through cumulative communication, exchange, and transfer among organizational employees over time. The leadership styles of managers not only generate unique organizational cultures but also influence the work attitudes of subordinates.

In strategic decision-making, management team members' strategic decisions influence not only the future implementation of strategies but also the future survival and development of the enterprise. Therefore, a tacit understanding between team members in terms of their perceptions, methods of risk assessment and control, and feelings is a crucial factor that influences decision-making. Although many studies have investigated strategic decision-making in enterprises, most have been based on decision content [8], core resources [8,9], and network relationships [10]. The decision-making behaviors of TMTs are influenced by objective facts and conditions such as investment environment factors, and also personal factors among team members such as the personality traits, thinking logic, and cognitive understanding of managers. Several studies have analyzed the selection of business strategies based on the characteristics of management teams [11,12] or risk perception [13]. However, few studies have simultaneously explored the causal relationships between TMT members' experience characteristics, mental models, risk perception, and strategic decision-making. Managers' backgrounds and experiences influence the strategic decisions they make [12]. In addition, managers apply mental models to comprehend various situations and predict strategic decisions [14]. Therefore, clarifying managers' experience characteristics and the mental models they use to interpret objective environmental situations and subsequently determining correlations between these characteristics and models could help to elucidate the effects of management team members' experiences on their decision-making processes and cognitive understanding. Second, decision makers' behaviors are a type of risk. Decision makers draw on their personal experiences when perceiving diverse and extensive sets of information and, consequently, form various interpretations of information and scenarios or adopt various mental models. The human limitation of being able to selectively perceive or remember only certain information causes decision makers to perceive risk differently from one another. Therefore, clarifying the correlation between managers' experience characteristics and their risk perceptions could help to elucidate the effects of experiences on team decision-making processes for risk assessment. Third, previous studies have found that experience characteristics, mental models, and risk perceptions directly influence strategic decision-making. However, the findings of these studies have failed to reveal whether the effects of experience characteristics on strategic decision-making are mediated by mental models or risk perceptions. The present study attempted to clarify the causal relationships between these factors (e.g., experience characteristics, mental models, and risk perceptions) to determine the strategic 
decision-making processes of enterprise TMTs. Finally, an increasing number of enterprises are shifting toward directly appointing managers from outside the enterprise to serve in TMTs rather than promoting managers from within the organization. Therefore, determining managers' sense of belonging within TMTs is imperative. In this study, psychological ownership was selected as the measure of the sense of belonging to determine whether psychological ownership influences strategic decision-making. The causal relationships between psychological ownership and strategic decision-making were examined to elucidate the role of psychological ownership in the strategic decision-making processes of TMTs.

\section{Literature Review}

\subsection{Managers' Decision-Making Behaviors}

A review of previous studies on managers' decision-making behaviors showed that the majority of these studies have proposed various influence factors based on perspectives such as transaction cost efficiency, resource-based value, network relationships, and core logic. These factors are mostly objective facts andconditions and variables of operating environments and enterprise resources. These studies have largely focused on the effects of these variables on managers' decision-making behaviors. However, analyses have revealed that the effects of these factors on various decision-making behaviors are largely associated with managers' characteristics and perceptions [11,13]. Conventional economic analysis assumes that managers make decisions to maximize economic benefits. However, several scholars have noted that in addition to economic analysis, other decision-making models exist [15], and different decision makers differ in their risk perceptions and decision-making styles [16,17]. When reviewing a large amount of diversified information, decision makers draw on selective cognition or memory based on their personal qualities and experiences. Their interpretations of different types of information are influenced by their understanding of and feelings regarding the information. Mental models control the coding and storage of information in managers' memories, thereby enabling them to quickly select and process useful information and make suitable decisions in specific situations [18]. When enterprises engage in strategic decision-making, their decisions are generally influenced by a number of uncertainty factors. These factors, coupled with time constraints and inadequate information, force decision makers to make subjective judgments and decisions based on their experiences. Therefore, different decision makers often make different investment decisions. Understanding the effects of managers' decision-making behaviors on their strategic decisions helps managers to avoid potential cognitive biases and behavioral traps in the decision-making process. In reality, the decision-making processes and outcomes of enterprises are influenced by not only objective transaction facts and environments but also the mentalities and personality traits of management team members. Consequently, the subjective traits and objective conditions of managers may affect or interfere with their decisions [1]. Strategic decisions are often affected by managers' personal experiences or other members of the management team, and this can lead to judgment errors. In addition, misjudgment may result from inadequate or erroneous data collected by the management team. Therefore, analyzing the differences among the background characteristics and subjective experiences of team members can elucidate the effects of human factors on strategic decision-making in relation to transaction costs.

The resource-based view emphasizes efficiency. The abilities, knowledge, and resources of individuals and enterprises are acquired and accumulated over time. Learning and development pathways differ among individuals and enterprises, as may the rate in which knowledge and abilities are accumulated [19]. Enterprises comprise management teams and employees. Management teams are responsible for making enterprise decisions. The cognitive foundations, values, and observations of team members and the interactive processes of these factors affect organizational competitiveness and behaviors. Strategy formulation is a key process in the development of an enterprise. Strategy formulation processes involve the knowledge and cognitive processes of team members and the 
sharing of mental models among team members. Management teams apply different models and select different competitive strategies for different environments and markets [20]. The resource-based view can be applied to explain the differences between the core resources that facilitate business performance. Managers' decision-making behaviors can explain the differences in core resources selected by team members based on their thought processes, cognitive models, and decision-making behaviors when enterprises have similar explicit behaviors. The network view focuses on relationships and ties. Networks are continuous and repetitive exchange relationships within organizations, between organizations, and between organizations and external environments embedded within organizations [21]. Enterprises can establish relationships and acquire valuable resources by being active in their networks, thereby establishing prominence within their networks [21,22]. Investment activities are vital channels for enterprises to establish network relationships with the external environment. Such relationships are maintained through interaction and exchange between enterprises. Subsequently, management team members form cognitive pools by sharing their trial and error experiences to achieve the sharing of mental models. Socialization enables management team members to share their business know-how, industrial norms and technologies, and differences between consumption characteristics. Therefore, the network view explains that enterprises acquire valuable market resources through network relationships. By contrast, managers' decision-making behaviors explain how management team members perceive markets, respond to demand, and make relevant strategic decisions in relation to the network relationships of enterprises.

\subsection{TMT Experience Characteristics and Strategic Decision-Making Behaviors}

A TMT is a group of key managers responsible for strategy formulation, planning, and execution. Generally, the upper echelons theory can be used to explain how TMTs make strategic decisions and the relationship between those decisions and business performance. Validating TMT characteristics can facilitate the prediction of organizational strategic decisions and business performance. Experience characteristics refer to members' cognitive foundations and values at a psychological level, as well as their age, professional history and experiences, professional background, organizational tenure, and international experiences [23,24]. Murray [25] asserted that any manager of the rank of deputy general manager or higher could be a TMT member [7]. Team members spend less time communicating and coordinating with other team members when the team has high age homogeneity. Conflict is also less likely to occur in such teams, and thus such teams are more likely to adopt high-risk strategies. Tenure experience refers to the amount of time a manager has held a single management position within a company [26]. Managers with less tenure experience require more time to learn enterprise practices. Therefore, teams with such managers tend to make conservative decisions. Management team members' professional histories and experiences refer to their previous professional domains. Managers typically draw on their experiences in these domains when making decisions. Management teams with a background in productivity primarily emphasize manufacturing, research and design, accounting, data processing, and information. Therefore, managers in such teams attach great value to organizational control and business efficiency and adopt strategies that provide them with a greater degree of control $[7,27]$. International experience refers to business management experience in a variety of countries and contexts. General international experience refers to management team members' ability to oversee the business activities of various overseas markets [28]. When members are familiar with the cultures and policies of other countries and maintain a broad worldview, they are more accepting of risk and tend to formulate more radical strategies [28]. Previous studies have reported that TMTs are more likely to prefer radial and high-risk strategies when members are similar in age, have more experience, come from productivity-related professional backgrounds, and possess substantial international experience. Therefore, the following hypothesis was formulated:

Hypothesis 1. TMT members' preferences for making risky decisions are positively correlated to the level of similarity among their experience characteristics. 


\subsection{Mental Models and Strategic Decision-Making Behaviors}

Mental models are intrinsic cognitive processes applied by individuals when performing an action in a specific environment. From the perspective of cognitive psychology, mental models are defined as an individual's internal representation of external reality [18]. Mental models are often used to predict specific behaviors under different conditions. Scholars often use mental models to interpret the causes of specific phenomena rather than religiously following the formal rules of logical reasoning [20]. A major reason that people rely on mental models stems from the limitations of individuals' underlying work-related memories. Applying formal rules of logical reasoning requires individuals to consider many possibilities. Using mental models to explain an individual's behavior reduces the level of conjecture regarding the individual's cognitive behaviors. However, this inference approach may not yield entirely correct or comprehensive findings [29]. In other words, people may develop different perceptions of the same matter because of differences in their mental models. Greca and Moreira [18] described mental models as models that people develop to explain real-world situations or events. Individuals apply mental models to ingeniously understand and explain phenomena. These models also serve as a reference for predicting individuals' behaviors.

In an organization, top managers' mental or cognitive understanding affects their understanding and selection of information, thereby influencing their strategic decisions. TMT members generally make decisions based on their existing cognitive foundations. Therefore, TMTs in different organizations usually create different organizational cultures. Previous studies have verified that managers' mental models influence their decision-making behaviors and organizational output [30]. TMTs make strategic decisions to achieve the development objectives of the enterprise. Thus, managers' mental models are vital factors that influence strategic decision-making [30]. Furthermore, a study on the effects of managers' mental models on strategic decision-making found that when TMTs value market competition, they are likely to adopt radical and high-risk strategies to quickly defend or retaliate against market competitors and ensure the survival of the company in a fiercely competitive market [31]. When TMTs value clients, they tend to formulate conservative strategies based on client demands to conform to consumer rights. When TMTs value their own opinions, they tend to formulate high-risk strategies that afford them more control rather than those that focus on competitors' behaviors or clients' opinions. Enterprise strategies change with the external environment; for example, collecting information on competitors and appropriately increasing client value are crucial elements for enterprises that require competitive strategies. Therefore, team members who pursue development prefer strategies that provide them with more control. Thus, the following hypothesis was formulated:

Hypothesis 2. TMT members' preferences for high-risk strategic decision-making are positively correlated with their preferences for development strategies.

\subsection{Risk Perceptions and Strategic Decision-Making}

Risk perception concepts suggest that the actions of decision makers may produce unexpected results. Therefore, decision makers' behaviors are a type of risk. Previous studies have noted that managers tend to define risk as the sum of possible losses, including financial, labor, and other tangible and intangible losses. Managers are often confident that they can hone their management skills and talent to control the occurrence of risk while continually revising their methods of evaluating target risk until the evaluation conforms to their original expected results. This concept has crucial implications for strategic decision-making [32]. Global trends are key factors that influence TMTs' international decisions. Therefore, TMT members' risk perceptions concerning external environments significantly influence their enterprises' strategic decision-making. Moreover, business experience, cultural differences, industrial structures, and systematic risk all influence the risk perceptions of management team members [33].

Business experience refers to experiences in business activity accumulated over time by TMTs. When external environments are controllable and market and competitor information are accessible, 
managers are better able to predict the potential outcomes of their decisions. Under such circumstances, managers are more likely to adopt radical high-risk strategies. Furthermore, in a highly competitive business environment, TMTs must be attentive to the number of competitors and the strategies adopted by competitors. Moreover, local politics and institutional environments or risks stemming from political unrest [34] are also factors requiring consideration when making strategic decisions. According to the resource-based view, whether the local government supports enterprise development is a major factor of consideration for TMTs during the decision-making process. If a government promotes policies that benefit business operations, such as tax exemptions on raw material imports, the provision of components and equipment, low wages, outstanding talent, and government subsidies, this reduces risk as perceived by TMTs and prompts TMTs to adopt radical and high-risk strategies. These uncertainties affect the future development of an enterprise, and the risk perceptions of TMTs affect strategic decision-making. Based on the preceding discussion, the following hypothesis was formulated:

Hypothesis 3. TMT members' preferences for high-risk strategic decision-making are negatively correlated with their risk perceptions.

\subsection{Mediating Effect of Mental Models and Risk Perceptions}

The compositional characteristics of TMTs significantly influence enterprise strategies and business performance [35]. Mental models are extrinsic behavioral manifestations of decision makers' cognitive understanding as influenced by their experiences [31]. Team members share their experiences with one another to determine common experiences, which are subsequently applied in mental models for market development and new strategy formulation [36]. According to social identity theory, individuals interact and communicate better and have less conflict with others of a similar age. Therefore, a team composed of members of similar ages is more likely to agree on a common decision [37]. Team members with more tenure experience are more familiar with the internal management of the enterprise and have more freedom to make decisions and more power to influence strategic orientation. Therefore, such team members are more capable of making decisions that are beneficial for the organization [1] and long-term coworkers are more likely to concede to strategic selections made by such team members. TMT members with business experience in overseas markets enhance the ability of the enterprise to handle overseas affairs and improve financial performance through international development [38]. Amidst economic globalization, development strategies are fundamental for ensuring the survival and competitiveness of enterprises. Members of a management team who are similar in age, have more tenure experience, and possess extensive international experience can share and accumulate similar experiences consistently, rapidly acquire the latest market information and competition conditions, make effective judgments, and quickly and effectively communicate and coordinate with one another. Most crucially, proposed development strategies are more likely to yield consensus in such a team. Therefore, the following hypothesis was formulated:

Hypothesis 4. TMT members' preferences for development strategies are positively correlated with similarities in their experience characteristics.

Decision makers may overestimate or underestimate risk or misjudge uncertainty, thereby causing them to make poor decisions. Subsequently, the characteristics and experiences of TMTs affect the risk perceptions of the team members [27]. Perceived differences may vary depending on the managers' backgrounds and experiences, eventually influencing their decision-making behaviors. When team members are similar in age, the similarities in their thought processes, backgrounds, and experiences enable them to more easily communicate, coordinate, and resolve team problems and conflicts. Improved communication quality reduces managers' risk perceptions, thereby increasing their willingness to take risks. Teams with more tenure experience have more time to establish a consensus 
because team members can draw on team experiences when making decisions, thereby reducing their perceived risk [2,24]. Management teams with a prominent background in productivity are concerned with manufacturing, research and development, innovation and improvement, and long-term investment, all of which facilitate innovation. Such teams are more accepting of potential losses, and thus have lower risk perceptions and higher willingness to take risks [27]. In teams with extensive international experience, members generally specialize in specific regional markets or overall international trends and are more confident operating in overseas markets. Such teams can minimize the perceived cost of uncertainty, and thus members often have lower risk perceptions. Considering this context, the following hypothesis was formulated:

Hypothesis 5. When formulating enterprise development strategies, TMT members' risk perceptions are negatively correlated with the similarities in their experience characteristics.

\subsection{Moderating Effect of Psychological Ownership}

Psychological ownership primarily refers to individuals' intrinsic (emotional and cognitive) sense of possession (i.e., mine-ness or our-ness) [39]. The definition of psychological ownership is slightly different to that of ownership in terms of the concept and motivations of possession. The sense of possession is omnipresent in psychological ownership, and the target of such possession may be tangible or intangible. This possession can be characterized as ownership that is seemingly legitimate but not governed by any existing laws [40]. When an individual's sense of possession is combined with his or her psychological feelings, the members of the organization may instinctively sense this ownership and attempt to apply these feelings to gain satisfaction, particularly when the target is part of the owner's psychological identification. This is psychological ownership [41]. When an individual's sense of possession is combined with his or her psychological feelings, members of the organization may instinctively sense this ownership and attempt to apply these feelings to gain satisfaction [42]. Psychological ownership is a type of attitude. Attitudes stem from individuals' personal values. For employees to apply their values to their team or organization, some employees require motivational stimuli, whereas others require the ascension of perception. In other words, employees are likely to exhibit psychological ownership when the following three basic requirements are met: (1) Workplace identification: a sense of home or belonging in the workplace; (2) efficiency and effectiveness: the right to control is satisfied; and (3) self-identity: expression of unique self-value and self-recognition [41,43].

Psychological ownership is essentially different from possession in terms of concept and motivation. The feeling of possession is omnipresent and can be associated with tangible or intangible "targets". Such ownership may or may not have a legitimate basis. In psychology, "target" refers to any tangible or intangible object of attachment. Attachment can stem from an individual or group. The object of attachment can be as small as a seat or as large as an organization or enterprise [42]. Previous studies have reported that psychological ownership influences individuals' behaviors and performance within an organization and their relationships with their work and their organization [40]. Therefore, ownership is mutually linked to individuals' behaviors and can be used to effectively predict individuals' actions. In other words, the feeling of self-regulation is part of an individual's psychological composition, or in other words, the result of self-efficacy [44]. A sense of control and action are the elements that enable tasks to be successfully completed. Therefore, when TMT members acknowledge their organization and its importance to them, they perceive organizational objectives as personal objectives [45]. Consequently, these objectives enhance members' self-efficacy and sense of responsibility and influence their subsequent behaviors, performance [42], and decisions. Employees assume responsibility for their duties and strive to produce the best possible results. Thus, employees with a high sense of psychological ownership have a greater ability to acknowledge the objectives of their organization and formulate appropriate organizational development strategies. Considering this context, the following hypothesis was formulated: 
Hypothesis 6. TMT members' preferences for high-risk strategic decision-making are negatively correlated with the similarities in their experience characteristics and psychological ownership perceptions.

\section{Method}

\subsection{Research Variables}

In this study, the effects of similarities in TMT members' experience characteristics, their strategic mental preferences, and their risk perceptions when making strategic decisions were analyzed. In addition, psychological ownership was adopted as a mediator to elucidate the effects of psychological ownership on the relationship between team members' experience characteristics and strategic decision-making. A questionnaire survey was conducted and scored using a 7-point Likert scale. The experience characteristics proposed by Terpstra and Yu [46] were adopted in this study. These were age, work background, international experience, and length of tenure. The effects of these characteristics on strategic decision-making were analyzed. TMT members were defined as deputy general managers, department directors, and other high-ranking managers. Similarities in experience characteristics were examined based on four items, namely age homogeneity, length of tenure, productivity-related work background, and extent of international experience. The average Cronbach's $\alpha$ coefficient of these items was 0.89 . The concepts proposed by Maignan and Lukas [47] were adopted to measure mental models. The strategic mental preferences of team members were observed, including competitor-based and client-based strategic objectives, the effects of these strategies on company decisions, and the environmental pressures stemming from these strategies. The mental model concepts proposed by Maignan and Lukas [47] were used to define team members' preferences for development strategies, or more specifically, preferences toward competitor-based or client-based strategies. The following four items were developed: actively guarding against competitors, enhancing client value, information acquired from strategies significantly influences company decisions (non-self-centered), and high environmental pressures stemming from strategies (market-driven). The average Cronbach's $\alpha$ coefficient of these items was 0.91. The risk perception concepts proposed by Brouthers [48] were adopted in this study to observe team members' risk perceptions regarding overseas investment and the effects of these perceptions on strategic decision-making. Five items concerning the risk perceptions of host countries were formulated, namely investment and business experience, cultural differences, industrial concentration, system stability of the host country, and ownership risk. The average Cronbach's $\alpha$ coefficient of these items was 0.92. Psychological ownership is a psychological state where individuals develop a sense of possession toward specific targets based on their experiences. Targets can be tangible objects or intangible ideas. The definition of psychological ownership proposed by Pierce et al. [41] was adopted in the present study. Psychological ownership was measured using three items. The average Cronbach's $\alpha$ coefficient of these items was 0.93 . The concepts of strategic decision-making proposed by Garnsey et al. [49] were adopted in the present study. Garnsey et al. explained that managers evaluate the strengths and weaknesses of an enterprise and the opportunities and threats of the environment before making a suitable strategic decision. Strategic decision-making was measured using three items. The average Cronbach's $\alpha$ coefficient of these items was 0.89 .

\subsection{Scope and Subjects}

The TMTs of China's top 1000 companies listed on the China Stock Exchange were selected as the research subjects. Companies' public statements and annual financial reports were analyzed to form a list of companies with TMTs. Questionnaires were submitted to these companies. A total of 698 companies satisfied the inclusion criteria and one questionnaire was submitted to each company. Thus, 698 questionnaires were administered. The questionnaires were administered via surface mail or email. Slight bias may exist in the research data because the identities of the respondents could not be validated. A total of 371 questionnaires were returned. After excluding invalid and incomplete 
questionnaires, 289 were retained. Among the respondents, 79\% were top managers and were men. The average age of the respondents was 53 years, and most worked in the electronics industry $(41 \%)$. The average length of employment was 17 years.

\subsection{Methodologies and Tools}

Structural equation modeling was conducted to process the data collected from the questionnaires. LISREL 8.54 software was adopted as the analysis tool for confirmatory factor analysis (CFA) and theoretical causal model analysis to validate the correlation and path coefficients between TMT members' experience characteristics, mental models, risk perceptions, psychological ownership, and strategic decision-making.

\section{Results}

CFA was performed to evaluate the overall measurement model. The results indicated excellent goodness of fit $\left(\chi^{2}=99.86, \mathrm{df}=94, p=0.07, \chi^{2} / \mathrm{df}=1.06\right.$, goodness of fit index $(\mathrm{GFI})=0.93$, adjusted goodness-of-fit index (AGFI) $=0.86$, comparative fit index $(\mathrm{CFI})=0.97$, non-normed fit index $(\mathrm{NNFI})=0.98$, root mean square error of approximation $($ RMSEA $)=0.026$, standardized root mean square residual $(S R M R)=0.031)$. The factor loadings $(\lambda)$ of the various measurement indices ranged between 0.73 and 0.92 . All indices achieved a factor loading of 0.7 or higher and a $p$ value of 0.001 or lower. The squared multiple correlation (SMC) was adopted as the reliability coefficient. All indices achieved an SMC value of 0.5 or higher, suggesting that the measurement indices adopted in this study had excellent reliability, effectively reflected the latent variables, and achieved excellent convergence validity. In addition, the construct reliability and average variance extracted (AVE) coefficients of the various latent variables were within an acceptable range. The construct reliability results showed that all the latent variables achieved a value of 0.7 or higher, suggesting excellent internal consistency. The AVE results revealed that all potential variables achieved a value of 0.5 or higher, suggesting that the measurement variables could appropriately explain the latent variables. Therefore, the latent variables achieved excellent construct reliability and validity. To achieve acceptable discriminate validity, the results for the between-group relationships of the latent variables in the measurement model were required to be lower than those of their in-group relationships. A relationship matrix was developed to test the between-group relationships of the latent variables. The results showed that the square root of the AVE was higher than in the between-group coefficients of the latent variables, suggesting excellent discriminate validity (Table 1).

Table 1. Correlation coefficient matrix of the latent variables.

\begin{tabular}{cccccc}
\hline Variable & $\begin{array}{c}\text { Experience } \\
\text { Characteristics }\end{array}$ & Mental Models & $\begin{array}{c}\text { Risk } \\
\text { Perceptions }\end{array}$ & $\begin{array}{c}\text { Psychological } \\
\text { Ownership }\end{array}$ & $\begin{array}{c}\text { Strategic } \\
\text { Decision-Making }\end{array}$ \\
\hline Experience characteristics & $\mathbf{0 . 8 5}$ & & & & \\
Mental models & $0.47^{* *}$ & $\mathbf{0 . 8 2}$ & & & \\
Risk perceptions & $-0.41^{* *}$ & $-0.45^{* *}$ & $\mathbf{0 . 8 4}$ & & \\
Psychological ownership & $0.39^{* *}$ & $0.47^{* *}$ & $-0.44^{* *}$ & $\mathbf{0 . 8 7}$ & $\mathbf{0 . 8 9}$ \\
Strategic decision-making & $0.43^{* *}$ & $0.41^{* *}$ & $-0.46^{* *}$ & $-0.43^{* *}$ & $\mathbf{0}$ \\
\hline
\end{tabular}

Note: $n=289$; ${ }^{* *} p<0.01$; The blackbody is the square root of the interpreted variance; the data below the diagonal is the correlation coefficient between the variables.

When the final model and its goodness of fit had been validated, the relationships between the latent variables were examined. Figure 1 shows that significant causal relationships existed among the latent variables. The analysis results indicated that the similarities in the team members' experience characteristics positively influenced their strategic decision-making. The path coefficient was 0.47 , indicating statistical significance $(t=4.357, p<0.001)$. Thus, H1 was supported. Moreover, team members' strategic mental preferences positively influenced their strategic decision-making. The path coefficient was 0.41 , indicating statistical significance $(t=4.064, p<0.001)$. Thus, $\mathrm{H} 2$ was supported. TMT members' risk perceptions negatively influenced their strategic decision-making. The path 
coefficient was -0.53 , indicating statistical significance $(t=-5.968, p<0.001)$. Thus, H3 was supported. The path coefficient for the similarities of TMT members' experience characteristics and their strategic mental preferences was 0.51 , indicating statistical significance $(t=5.847, p<0.001)$. Thus, H4 was supported. The similarities of TMT members' experience characteristics were negatively influenced by their risk perceptions. The path coefficient was -0.45 , indicating statistical significance $(t=-4.378$, $p<0.001)$. Thus, $\mathrm{H} 5$ was supported. Finally, the path coefficient concerning the moderating effect of psychological ownership on the relationship between similarities in TMT members' experience characteristics and their strategic decision-making was -0.57 , indicating statistical significance $(t=6.018, p<0.001)$. Thus, H6 was supported (Figure 1$)$.

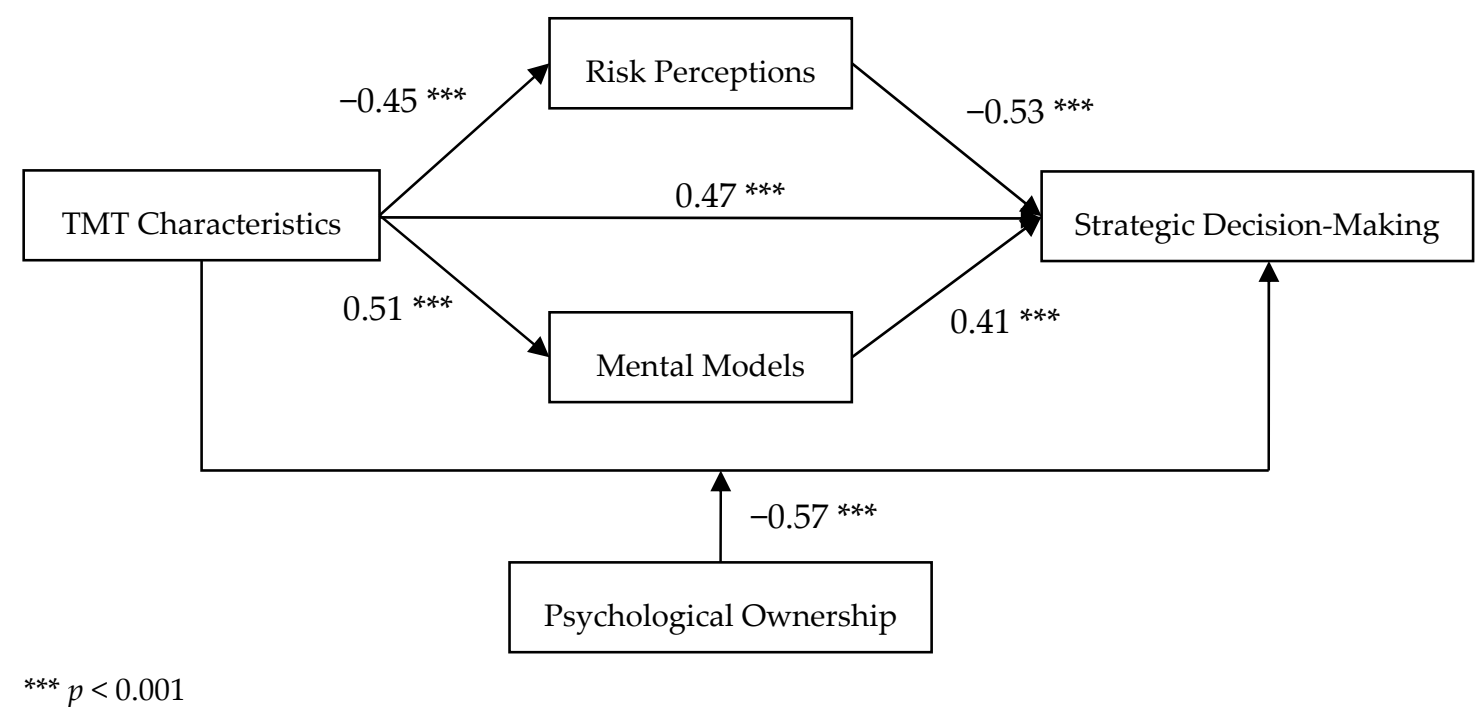

Figure 1. Model path diagram and standardized parameter estimations. TMT = top management team.

The multi-mediator model proposed by Brown [50] was used to evaluate the mediating effect of strategic preferences and risk perceptions. The model effects were classified into direct effects, total effects, total indirect effects, and individual indirect effects. The path coefficient for experience characteristics, strategic mental preferences, and strategic decision-making achieved statistical significance. The individual indirect effect of strategic mental preferences was $0.21(0.41 \times 0.51)$, which was lower than the direct effect of 0.47 , suggesting that the absolute mediating effect of strategic mental preferences was extremely limited. Furthermore, the path coefficient for experience characteristics, risk perceptions, and strategic decision-making achieved statistical significance. The individual indirect effect of risk perceptions was $0.24(-0.53 \times(-0.45))$, which was lower than the direct effect of 0.47 , indicating the presence of an absolute mediating effect of risk perceptions. A summary of the overall model revealed that the indirect effect of risk perceptions on strategic decision-making (0.24) was greater than that of strategic mental preferences on strategic decision-making (0.21). In other words, risk perception is the key mediator affecting the relationship between the similarities of TMT members' experience characteristics and their strategic decision-making.

\section{Discussion}

Previous studies on strategic decision-making have largely focused on transaction costs and the styles of decision makers. Although these studies have explained the objective environmental factors that influence enterprises and the core resources that influence strategic decisions, they have failed to discuss the influence of TMT members, who are the principal decision makers in a company, on strategic decision-making. The present study provided an alternative theoretical perspective by focusing on TMT members rather than non-enterprise individuals. This study analyzed several 
decision-making behavior variables from the perspective of decision-making (e.g., similarities in team members' experience characteristics, mental models, and risk perceptions) to examine strategic decision-making in companies. The findings confirmed that TMT members' experience characteristics, strategic mental preferences, and risk perceptions, as well as their enterprise ownership perceptions, influence their strategic decision-making processes. In addition, the findings revalidated the claims of previous studies that management team members' characteristics [38], mental models [20], and risk perceptions [33] are crucial factors that influence team members' strategic decisions. Therefore, team members draw on previously accumulated experiences to make strategic decisions. These decisions are the product of a strategic consensus fueled by team members' experiences and cognitive processes. They are the outcomes that pose the lowest risk as evaluated by team members. This study focused on the factors that affect decision-making processes rather than those that affect decision-making performance, particularly the effects of team members' cumulative experiences on their decisions concerning the arrangement of transactional activities or processes of value creation. For example, psychological ownership concepts were examined to determine whether TMT members' psychological ownership perceptions influenced their decision-making processes. The findings showed that when team members had high ownership perceptions of their enterprise (i.e., they perceived the enterprise as theirs), they were more careful when making strategic decisions and less likely to formulate radical high-risk strategies. Therefore, enterprises should strive to create an environment that generates a sense of belonging and prompts team members to identify with the organization and develop willingness to contribute to the organization unconditionally. Team members who establish a symbiotic bond with their enterprises are more careful when making strategic decisions and less likely to act impulsively. When making strategic decisions, team members' cumulative experiences and mutual understanding and awareness facilitate rapid judgment. However, these factors may also cause heuristic biases. A team with members who have more tenure experience, international experience, and similarities in terms of their professional backgrounds is more likely to achieve consensus. However, these factors could lead to member herding or confirmation bias, which refers to members selecting or collecting beneficial information and neglecting unfavorable or contradictory information to support themselves or reinforce team consensus, thereby causing determination biases. Nevertheless, when team members' experience characteristics are extremely different from one another, the team can acquire a broader range of information and achieve greater innovation. However, such differences can create more conflict. In teams with such differences, effective screening of critical information is crucial to eliminate bias. Understanding the composition and characteristics of team members' experiences can effectively prevent misjudgment and facilitate suitable decision-making. These concepts help enterprises identify the reasons for ineffective decisions and minimize erroneous decisions.

Finally, the findings revealed that in the decision-making processes of TMTs, members' experience characteristics, strategic mental preferences, and risk perceptions influence strategic decision-making. Moreover, the influence of experience characteristics on decision-making is mediated by risk perceptions. In other words, TMT members are generally more tolerant to external risk and more likely to formulate radical and high-risk strategies when their experience characteristics are similar. External environments are influenced by policies, supply and demand, and global trends. TMT composition characteristics should be associated with these factors. The risk awareness of members with an extensive worldview or more tenure experience is influenced by their cognitive experiences. Therefore, such members are more likely to formulate conservative strategies.

\section{Conclusions}

This study comprises three major practical implications. First, it serves as a basis for explaining the effects of similarities in management team members' experience characteristics, their strategic mental preferences, and their risk perceptions when making strategic decisions. In other words, similarities in management team members' experience characteristics, their strategic mental preferences, and their risk perceptions are all major factors that influence decision-making. Therefore, enterprises should 
consider not only objective factors such as market transactions and enterprise resources but also factors concerning team members.

Second, risk perception is a mediator in the relationship between similarities in management teams' experience characteristics and their decision-making behaviors. Risk perceptions are team members' subjective opinions regarding objective facts, and these opinions are affected by members' background characteristics and experiences. Therefore, different members adopt different cognitive understanding models and evaluation methods, both of which are reflected in their decision-making behaviors. Third, psychological ownership was confirmed to influence the similarities in team members' experience characteristics and their decision-making behaviors. A team generally comprises several members, each of whom has his or her own set of experience characteristics. Therefore, each member has a different sense of belonging in the enterprise. Crucial company decisions are typically formulated by the TMT. Members who are unable to identify with their organization are more likely to form erroneous strategies, consequently hindering company performance or causing problems. Therefore, enterprises should not only value the experience characteristics of team members but also strive to create a comfortable, respectful, and trusting work environment to enhance members' ownership perceptions, thereby improving the quality of their strategic decision-making.

The respondents of this study were members of TMTs in China's top 1000 enterprises. Management teams generally comprise two or more members, and different members may have different subjective opinions and, therefore, provide different responses to questionnaire items. Future studies could adopt management teams as the unit for analysis to compare the characteristics of members of the same team and elucidate how TMT members with different backgrounds form and share mental models within the team, as well as how conflicts stemming from different risk perceptions are resolved and how they affect final decisions. Moreover, the questionnaire recovery rate in this study was relatively low because of limited funding and time. Nevertheless, the outcomes of the statistical analysis performed in this study were acceptable, and the reliability and validity results were influential. Future studies could endeavor to increase sample recovery to enhance the reference value of research outcomes.

Companies may have standard procedures for formulating decisions. However, decisions in Taiwanese enterprises or TMTs are ultimately made by people. Therefore, to some extent, decisions are affected by the personality traits and experiences of the decision maker. These traits and experiences influence decision makers' thought processes and incite them to form different perceptions of specific events or objects. Consequently, these perceptions influence team decisions. Therefore, this study focused on the subjective experiences and cognitive factors of TMT members and decision makers. However, the factors that influence strategic decision-making include objective conditions and subjective behaviors. Future studies could combine all these factors when examining strategic decision-making to validate the relationships between the two factor types and elucidate the effects of these relationships on decision-making.

Acknowledgments: The authors are grateful to the valuable comments made by the reviewers. This research was supported by the National Natural Science Foundation of China (71702059, 71571074), Social Science and Humanity on Young Fund of the Ministry of Education (16YJC630136), and Education and Research Projects of Young and Middle-aged Teachers in Fujian Province (JAS160039), Ministry of Science \& Technology, Taiwan (104-2511-S-003-031-MY3 \& 106-2511-S-003-029-MY3).

Author Contributions: Tungju Wu and Yenchun Jim Wu conceived, designed, and wrote this paper. Yibin Li searched the research data, refined the collected data, and manipulated the data collected in software tools. Hsientang Tsai realized the analysis of the combinations and interpreted the data. All authors contributed to the closing of the article.

Conflicts of Interest: The authors declare no conflict of interest. 


\section{References}

1. Barker, V.L., III; Mueller, G.C. CEO characteristics and firm R\&D spending. Manag. Sci. 2002, 48, 782-801. [CrossRef]

2. Colbert, A.E.; Barrick, M.R.; Bradley, B.H. Personality and leadership composition in top management teams: Implications for organizational effectiveness. Pers. Psychol. 2014, 67, 351-387. [CrossRef]

3. Hambrick, D.C.; Mason, P.A. Upper echelons: The organization as a reflection of its top managers. Acad. Manag. Rev. 1984, 9, 193-206. [CrossRef]

4. Wowak, A.J.; Gomez-Mejia, L.R.; Steinbach, A.L. Inducements and motives at the top: A holistic perspective on the drivers of executive behavior. Acad. Manag. Ann. 2017, 11, 669-702. [CrossRef]

5. Jaw, Y.L.; Lin, W.T. Corporate elite characteristics and firm's internationalization: CEO-level and TMT-level roles. Int. J. Hum. Resour. Manag. 2009, 20, 220-233. [CrossRef]

6. Liu, Y.; Valenti, M.A.; Yu, H.Y. Presuccession performance, CEO succession, top management team, and change in a firm's internationalization: The moderating effect of CEO/chairperson dissimilarity. Can. J. Adm. Sci. 2012, 29, 67-78. [CrossRef]

7. Hambrick, D.C.; Cho, T.S.; Chen, M.J. The influence of top management team heterogeneity on firms' competitive moves. Adm. Sci. Q. 1996, 659-684. [CrossRef]

8. Williams, D.W.; Grégoire, D.A. Seeking commonalities or avoiding differences? Re-conceptualizing distance and its effects on internationalization decisions. J. Int. Bus. Stud. 2015, 46, 253-284. [CrossRef]

9. Sui, S.; Baum, M. Internationalization strategy, firm resources and the survival of SMEs in the export market. J. Int. Bus. Stud. 2014, 45, 821-841. [CrossRef]

10. Peng, M.W.; Wang, D.Y.; Jiang, Y. An institution-based view of international business strategy: A focus on emerging economies. J. Int. Bus. Stud. 2008, 39, 920-936. [CrossRef]

11. Abatecola, G. Untangling self-reinforcing processes in managerial decision making. Co-evolving heuristics? Manag. Decis. 2014, 52, 934-949. [CrossRef]

12. Kouamé, S.; Oliver, D.; Poisson-de-Haro, S. Can emotional differences be a strength? Affective diversity and managerial decision performance. Manag. Decis. 2015, 53, 1662-1676. [CrossRef]

13. Laufs, K.; Bembom, M.; Schwens, C. CEO characteristics and SME foreign market entry mode choice: The moderating effect of firm's geographic experience and host-country political risk. Int. Mark. Rev. 2016, 33, 246-275. [CrossRef]

14. Jarratt, D.; Fayed, R. The impact of market and organisational challenges on marketing strategy decision-making: A qualitative investigation of the business-to-business sector. J. Bus. Res. 2001, 51, 61-72. [CrossRef]

15. Kumar, V.; Subramanian, V. A contingency framework for the mode of entry decision. J. World Bus. 1997, 32, 53-72. [CrossRef]

16. Baron, R.A.; Franklin, R.J.; Hmieleski, K.M. Why entrepreneurs often experience low, not high, levels of stress: The joint effects of selection and psychological capital. J. Manag. 2016, 42, 742-768. [CrossRef]

17. Wennberg, K.; Delmar, F.; McKelvie, A. Variable risk preferences in new firm growth and survival. J. Bus. Ventur. 2016, 31, 408-427. [CrossRef]

18. Greca, I.M.; Moreira, M.A. Mental models, conceptual models, and modelling. Int. J. Sci. Educ. 2000, 22, 1-11. [CrossRef]

19. Cohen, W.M.; Levinthal, D.A. Adsorptive capacity: A new perspective on learning. Adm. Sci. Q. 1990, 35, 128-152. [CrossRef]

20. Karakaya, F.; Yannopoulos, P. Defensive strategy framework in global markets: A mental models approach. Eur. J. Mark. 2010, 44, 1077-1100. [CrossRef]

21. Park, S.H.; Luo, Y. Guanxi and organizational dynamics: Organizational networking in Chinese firms. Strateg. Manag. J. 2001, 22, 455-477. [CrossRef]

22. Wu, T.J.; Tsai, H.T.; Yeh, S.P. The role of manager's locus of control between perceived guanxi and leadership behavior in family business. Rev. Int. Sociol. 2014, 72, 87-104. [CrossRef] 
23. Naranjo-Gil, D. The role of management control systems and top teams in implementing environmental sustainability policies. Sustainability 2016, 8, 359. [CrossRef]

24. Hambrick, D.C.; Humphrey, S.E.; Gupta, A. Structural interdependence within top management teams: A key moderator of upper echelons predictions. Strateg. Manag. J. 2015, 36, 449-461. [CrossRef]

25. Murray, A.I. Top management group heterogeneity and firm performance. Strateg. Manag. J. 1989, 10, 125-141. [CrossRef]

26. Tihanyi, L.; Ellstrand, A.E.; Daily, C.M.; Dalton, D.R. Composition of the top management team and firm international diversification. J. Manag. 2000, 26, 1157-1177. [CrossRef]

27. Herrmann, P.; Datta, D.K. CEO experiences: Effects on the choice of FDI entry mode. J. Manag. Stud. 2006, 43, 755-778. [CrossRef]

28. Jahanshahi, A.A.; Brem, A. Sustainability in SMEs: Top Management Teams Behavioral Integration as Source of Innovativeness. Sustainability 2017, 9, 1899. [CrossRef]

29. Mercier, H.; Sperber, D. Why do humans reason? Arguments for an argumentative theory. Behav. Brain Sci. 2011, 34, 57-74. [CrossRef] [PubMed]

30. Gary, M.S.; Wood, R.E.; Pillinger, T. Enhancing mental models, analogical transfer, and performance in strategic decision making. Strateg. Manag. J. 2012, 33, 1229-1246. [CrossRef]

31. Santos, M.V.; Garcia, M.T. Organizational change: The role of managers' mental models. J. Chang. Manag. 2006, 6, 305-320. [CrossRef]

32. Duanmu, J.L. The effect of corruption distance and market orientation on the ownership choice of MNEs: Evidence from China. J. Int. Manag. 2011, 17, 162-174. [CrossRef]

33. Cesinger, B.; Hughes, M.; Mensching, H.; Ricarda, B.; Viktor, F.; Sascha, K. A socioemotional wealth perspective on how collaboration intensity, trust, and international market knowledge affect family firms' multinationality. J. World Bus. 2016, 51, 586-599. [CrossRef]

34. Brouthers, K.D.; Brouthers, L.E. Why service and manufacturing entry mode choices differ: The influence of transaction cost factors, risk and trust. J. Manag. Stud. 2003, 40, 1179-1204. [CrossRef]

35. Myung, J.K.; Choi, Y.H.; Kim, J.D. Effects of CEOs' negative traits on corporate social responsibility. Sustainability 2017, 9, 543. [CrossRef]

36. Murray, J.Y.; Gao, G.Y.; Kotabe, M. Market orientation and performance of export ventures: The process through marketing capabilities and competitive advantages. J. Acad. Mark. Sci. 2011, 39, 252-269. [CrossRef]

37. Burt, R.S. The network structure of social capital. Res. Organ. Behav. 2000, 22, 345-423. [CrossRef]

38. Nielsen, S. Top management team internationalization and firm performance. Manag. Int. Rev. 2010, 50, 185-206. [CrossRef]

39. Pierce, J.L.; Rubenfeld, S.A.; Morgan, S. Employee ownership: A conceptual model of process and effects. Acad. Manag. Rev. 1991, 16, 121-144. [CrossRef]

40. Van Dyne, L.; Pierce, J.L. Psychological ownership and feelings of possession: Three field studies predicting employee attitudes and organizational citizenship behavior. J. Organ. Behav. 2004, 25, 439-459. [CrossRef]

41. Pierce, J.L.; Kostova, T.; Dirks, K.T. Toward a theory of psychological ownership in organizations. Acad. Manag. Rev. 2001, 26, 298. [CrossRef]

42. Avey, J.B.; Avolio, B.J.; Crossley, C.D.; Luthans, F. Psychological ownership: Theoretical extensions, measurement and relation to work outcomes. J. Organ. Behav. 2009, 30, 173-191. [CrossRef]

43. Peng, H.; Pierce, J. Job-and organization-based psychological ownership: Relationship and outcomes. J. Manag. Psychol. 2015, 30, 151-168. [CrossRef]

44. Downes, P.E.; Kristof-Brown, A.L.; Judge, T.A.; Darnold, T.C. Motivational mechanisms of self-concordance theory: Goal-specific efficacy and person-organization fit. J. Bus. Psychol. 2017, 32, 197-215. [CrossRef]

45. Galvin, B.M.; Lange, D.; Ashforth, B.E. Narcissistic organizational identification: Seeing oneself as central to the organization's identity. Acad. Manag. Rev. 2015, 40, 163-181. [CrossRef]

46. Terpstra, V.; Yu, C.M. Determinants of foreign investment of U.S. Advertising Agencies. J. Int. Bus. Stud. 1988, 19, 33-46. [CrossRef]

47. Maignan, I.; Lukas, B.A. Entry mode decisions: The role of managers' mental models. J. Glob. Mark. 1997, 10, 7-22. [CrossRef] 
48. Brouthers, K.D. The influence of international risk on entry mode strategy in the computer software industry. Manag. Int. Rev. 1995, 35, 7-28.

49. Garnsey, E.; Stam, E.; Heffernan, P. New firm growth: Exploring processes and paths. Ind. Innov. 2006, 13, 1-20. [CrossRef]

50. Brown, R.L. Assessing specific mediational effects in complex theoretical models. Struct. Equ. Model. A Multidiscip. J. 1997, 4, 142-156. [CrossRef]

(C) 2017 by the authors. Licensee MDPI, Basel, Switzerland. This article is an open access article distributed under the terms and conditions of the Creative Commons Attribution (CC BY) license (http:/ / creativecommons.org/licenses/by/4.0/). 